\title{
REIVINDICACIÓN \\ EN LA NARRATIVA POLÍTICA
}

JESÚS GOMEZ SERRANO, José Guadalupe Posada: Testigo y Crítico de su Tiempo. Aguascalientes, 1866-1876, México, Universidad Autónoma de Aguascalientes/Secretaría de Educación Pública, 1995.

\section{I}

acia la década de los años veinte, con el surgimiento en Francia de la llamada Escuela de los Annales, se empezó a gestar una fuerte reacción en contra de la historia de corte político-narrativo. Ambos rasgos fueron en muchos países relegados de la práctica historiográfica por considerárseles "anticuados", pues su presencia -se decía- iba en contra de la "cientificidad" de la historia.

Empieza entonces a ganar terreno la historia cuantitativa, predominando las temáticas demográficas y económicas y dando gran importancia al procesamiento de datos por medio de las entonces nove- dosas computadoras. Así, se intentó la reinterpretación de periodos históricos de largo plazo que se median en siglos, dando énfasis a los llamados procesos de larga duración.

Uno de los efectos no deseados del auge de la historia cuantitativa, a la que por lo demás hay que reconocerle todos sus grandes méritos, fue que los libros de historia sólo eran leídos por un pequeño círculo académico, sin llegar a la gente común interesada en los temas históricos, para la cual las nuevas interpretaciones eran casi imposibles de entender.

En medio de este ambiente, la narración de historias políticas se vio relegada, argumentándose principalmente su poca capacidad explicativa, pues se le acusaba no sólo de no ocuparse del por qué de los acontecimientos que narraba, sino también de limitarse a la vida y obra de los "grandes hombres" 0 a la descrip- 
ción detallada y minuciosa de guerras y tratados políticos.

Con el paso del tiempo, sin embargo, la llamada historia cuantitativa ha dejado ver sus límites, pues aparte de que en muchas ocasiones no ha dado una explicación satisfactoria de los procesos históricos estudiados, aisló -como se señalaba mas arriba- a la práctica historiográfica del público, relegándola a estrechos círculos académicos.

Desde esta perspectiva, el nuevo libro de Jesús Gómez Serrano: José Guadalupe Posada: testigo y crítico de su tiempo. Aguascalientes, 1866-1876, aparece primero, como una reivindicación de la tan vituperada -por lo demás, a veces injustamente- historia política, así como un valioso intento por acercar la historia a un público más amplio y diverso.

La temática central del libro gira en torno a la vida política de Aguascalientes durante el periodo conocido como "República Restaurada" (1866-1876). El II Imperio encabezado por Maximiliano de Habsburgo ha llegado a su fin y el coronel Jesús Gómez Portugal entra triunfante a la capital del estado de Aguascalientes, tomando posesión de la gubernatura.

A partir de aquí el autor nos introduce, con estilo ameno y elegante, en todos los ires y venires de la política estatal; así conocemos desde los desatinos de la administración del coronel Gómez Portugal y la oposición de Ignacio T. Chávez a dicho gobierno, hasta la conspiración de Francisco G. Hornedo, el cual aprovecharía la coyuntura de la rebelión de Tuxtepec, encabezada por Porfirio Díaz, para encaramarse en la silla del gobernador y dar inicio, en Aguascalientes, a la época conocida con el nombre de "Porfiriato".

Desde nuestro punto de vista, el aspecto más original del libro es la forma en que se aborda este tramo de la historia política estatal, siendo aquí en donde se hace presente la figura de José Guadalupe Posada. Para estos años, Posada era un joven aguascalentense de origen humilde, al cual le tocó en suerte presenciar la singular forma de ejercer el poder de Gómez Portugal; testigo de su tiempo, a Posada no le costó mucho trabajo volverse crítico del mismo, pues alineado con la oposición del doctor Chávez, inició su carrera de grabador publicando, en un periódico de nombre El Jicote, una serie de dibujos destinados a criticar-muchas veces de manera despiadada- la marcha del gobierno local.

Así, a través de los grabados de Posada (trabajo suyo conocido muy poco a nivel nacional y reproducido a todo color en el libro) nos enteramos de las afi- 
ciones alcohólicas del coronel Gómez; de las manipulaciones electorales ejercidas por el gobierno; del arribismo de la clase política local, etcétera.

La utilización de la figura de Posada, sin embargo, no es un simple "pretexto" que se utiliza para introducir al lector en el tema y después olvidarse de él; tanto Posada como su hermano Cirilo son elementos de los que se vale el autor para recrear los sentimientos y sufrimientos del pueblo, de la gente común y corriente que lo mismo tenía que soportar los errores de sus gobernantes, que caminar por calles obscuras y llenas de hoyos cuidándose de los asaltantes, viendo como gobiernos y promesas iban y venían sin que mejorara su situación.

De esta manera se nos presenta un pasado vivo, lleno de incertidumbre, dudas y angustias, tanto para el pueblo llano como para sus gobernantes, los cuales son retratados no como héroes inmaculados o villanos consumados, sino simplemente como personas de carne y hueso, con debilidades y defectos, pero también con virtudes y principios que defender.

El autor, sin embargo, no se limita a ofrecer una narración vívida y amena de la política local; su experiencia como historiador y el conocimiento que tiene de la época le permiten explicar los hechos y situaciones que va narrando, señalando cómo las condiciones históricas que predominaban durante la época determinaron en buena medida la actuación de las personalidades políticas locales.

Es así como la narración y la explicación se entremezclan para conformar un texto de historia política, que alejado del lugar común de la ennumeración cronológica de batallas y periodos de gobierno y presentando de manera original y amena los hechos, puede contribuir a romper el aislamiento en el que muchas veces cae la historiografía, que acaba siendo leída por muy poca gente, las más de las veces vinculada a los ambientes académicos.

Por otra parte, si como quiere Alvaro Matute, "quien examina con cuidado un aspecto político del pasado puede obtener gran claridad para entender cuestiones o situaciones políticas del presente", está por demás señalar la pertinencia y la utilidad que tiene la historia política en un país como el nuestro, el cual está todavía muy lejos de resolver sus problemas en este campo de la actividad humana.

\section{Francisco Javier Delgado Aguilar DEPARTAMENTO DE HISTORIA/UAA}

1. Alvaro Matute, "Historia Política", en Varios, El historiador frente a la historia, UNAM, México, 1992, p. 70. 
